\title{
NORMATIVE ASPECTS OF RURAL DEVELOPMENT STRATEGY AND POLICY IN THE EUROPEAN UNION
}

\author{
Mieczyslaw Adamowicz ${ }^{1}$, Prof. \\ ${ }^{1}$ Pope John Paul II State School of Higher Education in Biala Podlaska
}

\begin{abstract}
The objective of the work is to define and evaluate the normative approach in the programming and implementation of rural development in the European Union countries. Main focus is to determine the objectives and methods of implementation and achieving these objectives in various ideological documents, strategies, programmes and development policies. The present work was created on the basis of documents and publications by community bodies and institutions as well as open literature on this subject. The study presents ways of defining rural areas, strategies and development programmes in Europe (Lisbon Strategy, Europe 2020 Strategy), tasks of major community policies towards rural areas (common agricultural policy, cohesion policy), Cork ideological declarations, multifunctional development concepts and smart development. Innovative approaches include the concept of smart city, smart village, smart specializations of regions and the urban-rural partnerships.
\end{abstract}

Key words: rural development, Cork declarations, rural policies, smart villages.

JEL code: $\mathrm{O} 2$

\section{Introduction}

The condition and development of rural areas is the result of socio-economic processes using local resources, external conditions and the scope of support resulting from the development policy. The rural development policy is built with the assessment of the current level and developmental capabilities. What proves necessary in making decisions and interventions in the pre-existing condition and socio-economic system, a positive approach (diagnosis, assessment of condition), as well as a normative approach including assessment of developmental opportunities and the concept and method of reaching the set objectives. The objective of the work is to define and evaluate the impact of normative approach in the programming and implementation of rural development in the European Union countries. Main focus is to define the normative definition of objectives, and methods of their implementation and achievement, in various ideological and conceptual documents and programmes as well as official development strategies. The normative character has a way of defining rural areas. However, the normative approach manifests itself mainly in formulated documents describing development concepts, as well as in strategies and policies that decide on the mobilization of economic and financial resources. The present analysis was carried out on the basis of documents and publications of the European Union bodies and institutions as well as the rich literature of the investigated subject. The study takes into account the strategic European development programmes (Lisbon Strategy, Europe 2020), the objectives of the main policies, including problems of rural development (common agricultural policy, cohesion policy), as well as ideological concepts referring to rural development (Cork declarations, multifunctional development, intelligent development, rural urban partnership), along with the new, innovative concept of smart villages.

\section{Defining rural areas}

The villages and rural areas have a spatial and territorial dimension, the scope and meaning of which for each of these concepts are different. Spatial approach stems from the assumption that rural space has features that make it differ from other spaces, and in this case from urban spaces. The territorial approach refers to space, specific local or regional systems based on, among others, the administrative division. There are no precisely defined definitions and perceptions of these 
concepts. However, it can be safely said that the concept of a village is narrower than the concept of rural areas. The village is primarily a settlement unit and remains in the dichotomy with the concept of the city. These two basic forms of settlement differ in many features, basic ones being morphological, demographic, socio-occupational, economic or cultural. The variety of these functions is not limited only to the area of housing, because these functions relate to the whole territory, which is integrally associated with the respective territorial settlement unit, where various production and service processes are organized. The village and the city perform different functions in their respective local and regional systems. Individual territorial systems compete for resources and development factors. Despite numerous attempts and efforts of both theoreticians and practitioners, no universal definition of the countryside and rural areas was developed so far. Definitions and criteria for delimitation are adapted to the purpose of the study and the nature of the problem or type of policy being carried out. The problem is not only to define the scope of rural areas but also their internal diversity, in other words the degree of rurality.

Among the many ways of perceiving, defining and classifying rural areas we should distinguish two main trends, an intuitive current and an objective current (Rakowska, 2013 p. 8). In the intuitive trend, there is a subjective perception of the village and it is understood as something obvious outside of the city, resulting from the dichotomous, eternal division of territories inhabited to the countryside and the city. The manner of defining this trend is understandable for everyone as a morphological, economic, social and cultural picture different from the picture of the city. The subjective trend may be a sufficient basis for sociological research, and often for the administrative separation of the village from the city. The objective trend is based on selected, more measurable criteria, according to the purpose and nature of the research. Despite many attempts to distinguish the concept of a village from a city with the help of numerous criteria, this two-part division is difficult because the city gradually penetrates into rural areas, resulting in a certain urban-rural continuity structure. Although the bipolar division of the country turns out to be outdated and inadequate to the content, it still has practical significance for the administrative division of local systems, as well as for the policy of financial support from national budgets and EU funds. This raises the need to set common criteria, both for research purposes and for the purpose of shaping the strategy and implementation of administrative tasks, as well as for conducting local and regional development policies and sectoral support policies.

\section{European policies towards rural areas}

Rural areas became the subject of interest of the Common Agricultural Policy (CAP), in which its second pillar, devoted mainly to the development of rural areas, was distinguished. This interest in rural areas within the framework of the CAP, which appeared in the 1970s, was strengthened mainly by the McShare reform, carried out in the first half of the nineties.

Prior to the McShare reform, the CAP was affecting rural areas through market instruments of the 1st Pillar. As a result of the reform there was an increased interest in structural problems, not only in agriculture, but also in its rural environment. The reform aimed at maintaining the population in rural areas, preserving the natural environment, protecting the traditional rural landscape and the model of family farming. The programmes of afforestation of agricultural land, and early retirement of farmers by granting them structural pensions, have become an important tool of this new policy. The market policy of the CAP 1st Pillar continued to absorb the majority of the funds allocated to support agriculture, and the actions towards rural areas were limited. At the 
beginning of the 21st century, there was some limitation of the role of market policy for the benefit of its structural counterpart. Agenda 2000, which was another reform of the CAP preparing the Community for the future enlargement to Central and Eastern Europe, defined the concept of a European agricultural model, in which farmers in accordance with social expectations should produce healthy and safe food with use of environmentally friendly production methods. At that time, the need to develop various forms of non-agricultural economic activity in the countryside was indicated, which gave rise to the concept of multifunctionality of agriculture and rural areas. It was pointed out that the shrinking importance of agriculture in the economic sphere (de-agrarisation of the village) should be balanced by the increase of its non-productive role, in the spheres of culture, landscape and other public goods. Taking the concept of sustainable development into account, an obligation to create integrated rural development plans was introduced, which should determine the impact of future agricultural activities on the economic, social and environmental situation of each country (European Commission, 2006 p. 4).

A continuation of the CAP system changes, initiated in 1992 and introduced by Agenda 2000, the so-called Fischler reform, adopted in 2003 in Luxembourg, deepened the changes in the sphere of agricultural support under 1st Pillar of the CAP and strengthened the regulations covered by the 2nd Pillar II and concerning rural development. It can be said that a new rural development policy has emerged, which emphasizes innovation in agriculture and sustainable development of agriculture, forestry and other sectors functioning mainly in rural areas. The new common agricultural policy, implemented since 2005 after the fifth enlargement of the European Union, drew attention not only to the promotion of the sustainable agriculture system, the quality of food and detachment of direct payments from the size and structure of production, but also to animal welfare, preservation of cultural values of villages, traditional plant varieties and animal breeds, and other elements of material culture in rural areas.

The 2008 review of the assumptions of the CAP instruments, known as "Health Check", was aimed at identifying ways to simplify and improve the efficiency of the direct payment system, and include farmers from Central and Eastern Europe therein. Health Check confirmed the need to further foster the process of shifting funds from market policy to rural development needs. New areas of interest are climate change, renewable energy production, water deficit prevention and risk insurance issues.

The policy of the European Union towards rural areas planned for the years 2007-2013 retains the continuity of previously implemented programmes. Each Member State has prepared its national strategic plan, constituting a reference framework for EU rural development programmes. Three thematic axes have been distinguished in these programmes: the axis on competitiveness and the environment, the axis on land management and the axis encompassing economic diversification and quality of life. An axis under the name Leader was also introduced. The third axis covering - economic diversification, quality of life and the Leader axis contained instruments concerning rural development policy. This last axis became the main tool for rural development policy in later years. Each of the axes contains a specific number of partial actions. The objective of the economic axis is to support modernization, innovation and efficiency of agricultural production, the environmental axis is intended to improve the condition of natural environment in rural areas. The activities of the social axis were focused on the diversification of rural economy, while in the framework of the LEADER approach, attempts have been made to seek new methods of economic and social activation in the countryside. 
The 2007-2013 strengthening of rural development policy was supported by the establishment of the European Agricultural Fund for Rural Development, which simplified the rules for providing assistance and increased the coherence of the support instruments used. Member States have also obtained a considerable degree of freedom in shaping the structure of objectives and expenses. One should also pay attention to the necessity of greater involvement of own resources of beneficiaries and to the increase of the activity and participation of rural residents in the implementation of socio-economic programmes. The second pillar of the CAP is more decentralized and is based on the principles of partnership. The partnership exists at the level of relations between EU bodies and Member States, and includes direct cooperation between EU bodies with regional and local authorities, between public authorities and economic and social organizations representing civil society. The principle of subsidiarity, which motivates European integration, is reflected in this cooperation and partnership.

Although effective integrated rural development programmes and consolidated sources of financing have not been developed so far, a character consistent with the essence of sustainable development has been given to the rural development policy, which takes equal account of the economic, social and environmental aspects. The aim of sustainable development of rural areas is also to maintain proper proportions between ad hoc tasks, such as increasing the competitiveness of a given territorial system, and in particular increasing employment opportunities, and long-term tasks such as shaping the social, economic and environmental integrity of the area.

The Rural Development Programme for 2014-2020, adopted in 2013, is basically a continuation of the support programme from the previous financial perspective. The changes mainly concern the organization and implementation of individual instruments as well as the system for monitoring and evaluating the implemented activities. The currently implemented programme was integrated in the overall development policy system, as outlined by the "Europe 2020 - Strategy for smart and integrated inclusive development". The main objectives of the 2014-2020 RDP are to improve the competitiveness of agriculture, balance natural resource management and climate action, and sustainable territorial development of rural areas. The programme implements the following six priorities of the EU rural development policy:

1) Facilitation of knowledge transfer and innovation in agriculture, forestry and in rural areas;

2) Improving the competitiveness of all types of farming;

3) Improving the organization of the food chain and promoting risk management;

4) Restoring, protecting and strengthening ecosystems dependent on agriculture and forestry;

5) Active resource management and transition to a low-carbon and climate-resilient economy in the agricultural and forestry sectors;

6) Increasing social inclusion and reducing poverty.

\section{Declarations relating to the basics of rural development}

The conferences devoted to the agricultural perspective of Europe organized in Cork, Ireland have a strong impact on the shape of the concept of rural development policy. The first Cork declaration announced in November 1996 indicated the need to create integrated rural development policy; the second one of August 2016 defined the outline of the policy of shaping better living conditions in rural areas. The 1st, 1996 Cork Conference entitled "Rural Europe Future Prospects" determined the basic directions and principles for development of rural areas in Europe, which were included in the form of a declaration, according to which rural development 
should be sustainable and balanced, with territorial orientation. It is believed that rural areas and their inhabitants are a real, valuable resource of the European Union with competitive capabilities. Taking the important role of agriculture and farmers in respect to natural environment into account, it was noticed that the contribution of agriculture and forestry sectors in rural economy was reduced, while the importance of non-agricultural sectors of the countryside economy increased. The development of rural areas should consist of economic diversification, run by small and medium enterprises, mainly of the services sector. Diversification of economy, but also rural and cultural landscapes, as well as the development of new functions should secure a higher standard of living for the rural population, and protection of natural resources and biodiversity.

The new model of rural development under the name of LEADER included 10 items in the form of postulates. They involved: preferences for rural development; integrated approach towards development; diversification; applying the principle of sustainable development; principles of subsidiarity, simplification, programming, financing, management as well as research and evaluation. The 1996 Cork declaration was to make European politicians aware that the rise of public belief to start a new rural development policy, the increase of the attractiveness of rural areas, and creating more significant centres for life and work for people of all ages, as well as the functioning of new professions are required. The proposed new model of rural policy differed from the CAP model that was implemented at that time. The economic and social diversification was to be made possible with aid focused on investments and services-related economic activities, development of education and training systems, improvement of the information and communication system. The needs for simplification of assistance procedures, concentration of resources, and proportionality in relation to the developmental backwardness, were all noticed. The principle of subsidiarity meant the aspiration to decentralise activities and strengthen the role of local communities in programming and development management. Simultaneously, the declaration emphasised the importance of agriculture for the overall level of rural development, the necessity of its contribution in the achievement of all economic, social and environmental objectives. Duties such as protection of environment and biodiversity, and the preservation of landscape and cultural values of villages, as well as the increase of the standard of living of rural communities were also imposed on agriculture. The outlined agricultural development model became multifunctional. The 1996 Cork Declaration indicated the need to strike a balance between production objectives related to the development of agriculture and ensuring food security, and the protection of environmental resources as well as the development of non-agricultural economic activities and social functions of rural areas. The declaration became the foundation for shaping rural policy under Agenda 2000, which prepared the Community for its fifth enlargement to Central and Eastern Europe. In this period, the CAP adopted the most important assumption of the Cork Declaration of multifunctional, sustainable development based on the use of endogenous potential of rural areas, as well as external funding and support instruments.

In addition to the well-known and universal concept of sustainable development, on which all Community policies are based, including the CAP, the concept of multifunctional rural development is significant and capacious. The main assumption of this concept is the gradual departure from the domination of agriculture in the structure of the rural economy by development of additional, nonagricultural forms of economic activities and various functions of social services. Thus, on one hand, this concept assumes the support for the agriculture modernization process, and on the other the acceleration of development of non-agricultural activities, which results in the general 
diversification of the rural economy. The expansion of this way of thinking in the 1970s initiated the post-productivist stage of development, characterized by the growing significance of diverse functions and activities in the services sector (Woods, 2005 p. 14). W.Stola included the following to the main functions of rural areas (Stola, 1999 p. 169):

- residential functions - the village is a place of residence not only for farmers, but also for people not related to agriculture, who undertake professional activities outside their place of residence,

- production functions - production of high-quality and safe food and agricultural raw materials,

- service functions - improving the quality of residents' life and constituting a source of income for people employed outside agriculture,

- recreational functions - based on the use of natural and cultural resources for spending free time and recreation,

- tourist functions - implemented mainly in the form of agrotourism and eco-tourism,

- cultural functions - physical and intangible resources of local culture related to work, life, traditions and rural rites,

- environmental functions - protection of biodiversity and natural resources,

- aesthetic functions - arising from the beauty of the landscape and cultural monuments.

Multifunctionality of rural areas and agriculture was focused on improving economic effects (new jobs, higher income), which also bring beneficial social effects (greater attractiveness of rural life, inhibition of population outflow). The development of non-agricultural functions should be correlated with the local resources and endogenous potential as well as bottom-up character. Multifunctionality applies to entire rural areas as well as agriculture itself and the respective farms. The multifunctional effects may emerge in the form of commodities and non-market products, often of a conjugate character, which provides social benefits, including public goods (Adamowicz, 2004 pp. 29-30).

The practical implementation of the concept of multifunctional rural development requires its integration with the current policy, in this case the common agricultural policy and cohesion policy, as well as the inclusion of this concept in the spatial development system and environmental protection. Multifunctional rural development should be a process that occurs on many levels. Including spatial, social and economic changes that enable residents to obtain income from professional activities and improve the quality of their life (Stanny, 2012 p. 150). This development should be connected with principles of market economy and competitiveness, which does not mean that the need to support through rural policy is rejected. As a complex process, it requires proper programming and spreading over time. The concept of multifunctional development is constantly being supplemented and enriched, while maintaining its essence. This should be treated as the aspiration of the scientific and political environment shaping the development of agriculture and rural areas, as expressed in the 2016 second Cork Declaration. 2nd Cork Declaration on "A Better Life in Rural Areas" consciously referred to the first, but it also emphasized new elements, such as innovation, integration and indications relating to agricultural policy as well as rural policy.

The authors of the declaration expressed their conviction that Europe's rural resources will be able to meet current and future challenges in supplying European Union citizens with quality food, keeping the rural economy in a closed cycle, expanding the bioeconomy, using resources more efficiently, overcoming the difficulties resulting from climate change, and reduction of dependence on non-renewable energy sources. The authors expect a wider base for the rural economy in 
increasing digitization, knowledge resources, innovations and bottom-up entrepreneurship. Agriculture and forestry, while still remaining important sectors of the rural economy, will be able to engage in emerging new value chains and rural areas will be recognized by young people as an attractive place to live and work. Determined by the need to utilize local potential and bottom-up development initiatives better, they also point to strengthening of the strategic focus on the selection of objectives and instruments for rural development policy. Innovative, integrated and inclusive policy for rural development and agriculture should be oriented on the following priorities.

1) Promoting rural well-being - resulting from the potential of the village to provide innovation and favourable solutions to current and future challenges in the sphere of economics, food security, climate change, resource management, social exclusion, and migration problems.

2) Strengthening of rural value chains and cooperation networks in the sphere of new rural business areas. This should provide new opportunities for agriculture, forestry and related enterprises in the context of circular, green and energy efficient economy.

3) Investing in strengthening rural life and vitality, which means focusing on investing in creating added value for the society. Investments in the countryside, both private and public, in infrastructure and development potential, should be directed towards common objectives such as job creation and green and inclusive economic growth.

4) The preservation of the rural environment, especially regarding the proper management of land resources, provision of public goods and strengthening of its natural and cultural heritage.

5) The management of natural resources such as water, soil and biodiversity so as to meet the growing demand for food, fodder, fibres and other biological materials. This requires the use of sustainable and cross-sectoral management, involving mainly the agricultural and forestry production.

6) Encouraging actions to prevent and mitigate adverse climate change. These activities are related to the sequestration of coal in rural areas and the management of low-emission economy.

7) Embrace the knowledge-based economy and innovations. It is about access to the right technologies, effective management methods, and achieving economic, social and environmental benefits, both through education and consulting.

8) Strengthening rural self-government and the efficiency of local administration. This sphere of strengthening rural potential should be based on the use of the LEADER programme, the European Partnership for Agriculture and local grassroots initiatives by providing technical assistance, training, cooperation and networking.

9) Advanced delivery policy and simplification of production processes. This also applies to the procedures and rules for the implementation of the common agricultural policy, and the use of smart procedures and tools for local and regional administration. An important role should be played by management with use of electronic tools.

10) Improving efficiency and responsibility. Public support for agriculture and rural areas must be subject to monitoring and reliable evaluation. This assessment should relate to the benefits of the actions taken, the efficiency of the use of the funds, and the overall assessment in the light of the assumed objectives.

Participants of the conference and the makers of the Cork 2 declaration draw the attention of creators of rural development policy to the need of strengthening of public awareness of the potential of rural areas, for their general development and the challenges they face. 


\section{Innovative and smart development concepts}

In its pursuit of maintaining and increasing its position in global competition European Union adopted the 2000 Lisbon Strategy, that aimed at making economic development more dynamic, creating a knowledge-based economy, guaranteeing the growth of competitiveness and employment levels, ensuring social cohesion and caring for sustainable development and natural environment. The implementation of this strategy failed to bring the expected results, which was the reason for its update after just several years and the correction of its provisions. The list of strategic goals was narrowed down to two, directed at achieving sustainable economic growth and sustainable employment growth. A number of financial and legal-institutional instruments as well as activities in the form of operational programmes financed from Community funds were used to achieve these objectives. The global financial crisis of 2007 nullified the achieved effects and hindered further implementation of the Lisbon Strategy, while at the same time revealing the structural weaknesses of the European economy. Due to the need for changes the European Council adopted, in June 2010, its new strategy for smart, sustainable and inclusive, the EUROPA 2020 strategy.

When preparing the strategy, the European Commission proposed to implement, till 2020, the five objectives incorporated into the national development strategies, including; activities in the areas of employment, research and innovation, climate change and energy, education and the fight against poverty. Three interlinked priorities were established in the Europe 2020 strategy itself:

- smart growth - development of the economy based on knowledge and innovations;

- sustainable growth - signifying the development of an economy using available resources effectively, a greener and competitive economy;

- nclusive growth - encouraging greater employment, ensuring social and territorial cohesion.

Specific parameters and the criteria for the respective parameters were established, all of which are also applicable to agriculture and rural areas. Within each of these three priorities, a number of objectives were established, and these were then grouped in seven separate flagship initiatives:

- "Innovation Union", to simplify the framework conditions and access to the research and innovation financing required to produce new goods and services, which create employment and economic growth;

- "Youth on the move from school to work", serving the improvement of education systems preparing for the profession and facilitating youth's access to the labour market;

- "A Digital Agenda for Europe", to accelerate the dissemination of broadband Internet to exploit the benefits of computerization in enterprises and households;

- "Resource efficient Europe", aimed at decoupling growth from the use of traditional resources and facilitating the transition to a low-carbon economy, the wider use of renewable energy sources, modernizing the transport sector, promoting greater energy efficiency;

- "Industrial policy for the globalization era", facilitating and improving the business environment for small and medium enterprises and strengthening the competitiveness base in the conditions of globalization;

- "An Agenda for new skills and jobs", aimed at modernizing labour markets and equipping people with incentives for lifelong learning and better matching labour demand and supply through increased employee mobility;

- "A European platform against poverty", reinforcing social and territorial cohesion, facilitating access to work and living in dignity. 
Three of these flagship initiatives refer directly to the priority for smart growth. Smart growth means strengthening knowledge and innovation as the driving forces for future development. This requires improving education, strengthening research, promoting innovation, and knowledge transfer across the Union, making full use of information and communication technologies, and ensuring that innovative ideas can be transformed into new products and services that will contribute to economic growth, quality improvement and meet the various challenges of modern times. The activities of this priority can be implemented at the Community, national and regional levels.

The flagship initiative 'Youth on the move from school to work' aimed to increase the attractiveness of European higher education institutions, and to raise the general level of education and vocational training, which are necessary to increase youth mobility, and to facilitate its entry into the labour market. The flagship initiative 'A digital agenda for Europe' agenda aimed at disseminating modern information technologies by 2013 and providing access to an even faster Internet by 2020. As part of the Europe 2020 Strategy, a 'European Innovation Partnership' document was developed in 2012 to strengthen sustainability and productivity in agriculture. It was included in the European rural development policy and in the Horizon 2020 European research programme.

New ideas have emerged in Europe, in the last decade, aimed at saving resources through appropriate spatial planning, organization of transport flows, reduction of costs resulting from the sprawl of cities and others (Stawasz, Sikora-Fernandez 2015 pp. 11-13). It is about concepts, such as the "smart city" or the "smart housing estate". The concept of smart specialization of the region found its practical implementation within the framework of the Europe 2020 Strategy. Among the newest one, the concept of "intelligent village" should be mentioned.

With regard to smart cities, attention is pointed to the use of innovations and information technologies to build interactivity and efficiency of urban infrastructure. In building smart cities, the need to invest in human capital and social capital, communication infrastructure, strengthening economic sustainable development, rational use of resources and participation of citizens in development programmes were all pointed out. The following six elements were distinguished in the intelligent city model: environment, people, quality of life, management, mobility, economy and research, innovation, creativity, high productivity and efficiency. N. Caminos, as one of many authors, defines a smart city as a territory with high potential for learning and innovation, equipped with the creativity of its residents, with institutions creating knowledge, communication infrastructure and effective management (Caminos 2008 pp. ).

As part of the "Smart Growth" priority of the Europe 2020 Strategy, the concept of smart specializations for countries and regions was developed. This concept was incorporated in other strategies and included in the financing framework of the 2014-2020 financial perspective (Adamowicz, 2016 pp. 5-15). The concept of smart specializations of regions took shape in 2008, and in 2010-2014 it was developed and included in the Europe 2020 strategy (Kardas, 2014 pp. 211-135).

The idea of smart specialization is based on the assumption that EU Member States, or any other region, cannot independently achieve satisfactory results in all areas of the economy, especially in the sphere of new technologies and innovations (Pilarska, 2014 pp. 59-82). Smart specializations provide opportunities to achieve economic growth in all regions or countries, both those better, and those less developed. This conception has two sides. The first requires 
concentration on selected areas, where the existing potential is to be fully exploited, and the second requires concentration on specific domains in order to coordinate specific and original areas of competence in the region (Foray et al., 2011).

The vision of rural areas, as outlined in the 2016 second Cork Declaration "Better life in rural areas" acknowledged the ongoing differences between the city and the countryside, especially in the field of digitization, transport, communication, stage of service development and others. The Cork 2 Declaration became the basis for reflection on the future of villages in EU Member States. An attempt to create a vision of sustainable development of rural areas resulted in the conception of "smart villages". The conception is now becoming an integral part of the development strategies of regions and territories. Strengthening the integration between the city and the countryside forms the crucial factor for the effectiveness of this concept. It is also crucial to integrate the various activities already implemented into a coherent program. The intention is to build something more solid than simple stunting, to provide a transparent interpretation for politicians, entrepreneurs and other stakeholders in order to determine the needs and development opportunities of individual territorial systems. The conception of smart villages includes both rural settlements and surrounding rural areas. It includes rural communities and existing resources in terms of creating new development possibilities. Traditional as well as the new connections of this conception are supported by digitization, information technologies, innovations and better use of knowledge for developing benefits for entrepreneurs and people. The proposed conception does not have the character of a single model combining infrastructure investment, development of entrepreneurship, human capital and capital building inherent in local communities. Concluding, the implementation of the idea of "smart village" brings awareness to computerization, access to healthcare and other basic services, innovative environmental solutions, management of agricultural waste in the closed cycle, promotion of local products with use of information technology, implementation and use of smart specializations in agriculture, food economy and tourist and cultural activities. The conception can be implemented under the common agricultural policy, cohesion policy, science policy, transport policy and social policy.

In many countries, the regional governments play a major role in the process of managing Community funding. Lower administrative levels have rather an auxiliary function in the process of managing European funds. And it is exactly at this local level, that the specific factors and barriers to rural development are located, and the non-agricultural functions develop. However, rural areas itself are unable to create functionally related territories with development potential. The development policy covering rural areas remaining in symbiosis with the cities located among them offers more comprehensive options. The rural-urban partnership requires closer coordination and cooperative integration of the agricultural policy and regional policy.

The urban-rural partnership might be an important factor to strengthen the territorial cohesion. This conception was reflected in the 2020 Territorial Agenda of EU, and in the 2013 OECD report entitled "Rural-urban partnership: an integrated approach to economic development" (OECD, Rural - Urban ..., 2015). At the first stage this report highlights the need to define the functional regions of spatial structure, in which relations, interdependencies and interactions between the city and the countryside occur

The European Cohesion Policy, modified in 2014, emphasises the integration of activities and the use of structural funds and agricultural funds in territorial systems. Multipronged territorial potentials should be adjusted to the size and character of the territorial system. These aspects 
might go beyond formal administrative boundaries. For this to happen, it is necessary to have real interest and involvement of both local government authorities and various partners, including interest groups.

An outline overview of various strategies, ideological conceptions and rural development programmes shows that this issue is still alive and important, not only for rural residents, but also for the whole society as well as regional and national economies. The constant occurring of new conceptions reflects to the dynamics of change in rural areas, and the importance of these areas for European Union countries, as well as strengthening of their position in the world.

\section{Bibliography}

1. Adamowicz, M. (2004). Wielofunkcyjne gospodarstwa rolne jako podmiot w rozwoju wsi i rolnictwa (Multifunctional farms as an entity in the development of the village and agriculture). In: Wiejskie gospodarstwa domowe w obliczu problemów transformacji, integracji i globalizacji (Rural households in the face of problems of transformation, integration and globalization). Warszawa: Wyd. SGGW.

2. Adamowicz, M. (2016). Smart Specialization as a Way of Strengthening the Innovation Potential of Regions, Acta Scientiarum Polonorum Oeconomia 15 (4).

3. Caminos, N. (2008). Intelligent Cities and Globalisation of Innovation Networks. London and New York: Routledge.

4. EU Action for Smart Villages (2017). European Commission.

5. Foray, D., David, P., Hall, B. H. (2011). Smart Specialisation: From Academic Idea to Political Instrument, the Surprising Career of a Concept and the Difficulties Involved.

6. Kardas, M. (2014). Inteligentna specjalizacja - nowa koncepcja polityki innowacyjnej (Intelligent specialization - a new concept of innovation policy), Optimum, Studia Ekonomiczne, 2 (50).

7. Polityka Unii Europejskiej w zakresie rozwoju obszarow wiejskich na lata 2007-2013 (European Union policy in the field of rural development for 2007-2013) (2006). Luksemburg: Komisja Europejska.

8. Rural Urban Partnerships: An Integrated Approach to Economic Development (2013). OECD.

9. Pilarska, Cz. (2014). Koncepcja smart specialisation w polityce ekonomicznej Unii Europejskiej (The concept of smart specialization in the economic policy of the European Union), Studia Europejskie, 4.

10. Rakowska, J. (2013). Klasyfikacje obszarow - kryteria, definicje, metody delimitacji. Studium metodycznostatystyczne (Classifications of areas - criteria, definitions, methods of delimitation. Methodological and statistical study), Warszawa.

11. Sołek, K. (2017). Oddziaływanie funduszy europejskich na proces rozwoju społeczno-gospodarczego obszarow wiejskich wojewodztwa podkarpackiego. Rozprawa.doktorska. (Influence of European funds on the process of socio-economic development of rural areas of the Podkarpackie Voivodeship. Dissertation). Warszawa: SGGW.

12. Stanny, M. (2012). Spoleczno-ekonomiczne zrównoważenie obszarów wiejskich (Socio-economic sustainability of rural areas). In: Raport o stanie wsi. Polska Wieś (Report on the state of the village. Polish Countryside). Warszawa: Wyd. Naukowe Scholar. 